\title{
Quality Assessment of Chia and Basella alba (L.) based Complementary Food Formulation
}

\author{
Laxmibhai Belagali ${ }^{1}$ and Usha Ravindra ${ }^{2^{*}}$ \\ Department of Food Science and Nutrition, UAS, GKVK, Bangalore, India- 560064 \\ *Corresponding author
}

\begin{abstract}
A B S T R A C T
\section{Keywords}

Complimentary food, sensory evaluation, nutrients, antinutrients, chia, basella

\section{Article Info}

Accepted: 05 April 2020 Available Online: 10 May 2020

Promotion of optimal growth in infants calls for introduction of adequate food supplements in the form of complementary foods in addition to continued breast feeding from the age of 6 months onwards as complementary feeding plays critical role in children. Study was carried out to develop complementary food formulation, sensory evaluation, nutrient and antinutrients analysis. Finger millet, oilseeds, milk solids, jaggery, processed chia seeds and basella alba leaves were used in different proportion. Quality parameters were analyzed using AOAC and other protocols. Results revealed that complimentary food formulation I (soaked and dried chia seeds incorporation) received best acceptance than complimentary food formulation II and differed significantly. Best accepted formulation I had moisture 14.35, protein 28.3, fat 18.8, ash 3.4, crude fiber 3.64, carbohydrate 31.56 per cent respectively and energy $407 \mathrm{Kcal}$ per $100 \mathrm{gm}$. The calcium content -302 , zinc 5.92 and iron $2.7 \mathrm{mg} / 100 \mathrm{~g}$ respectively. Polyphenol, tannin and phytic acid content were $0.84(\mathrm{mg} / 100 \mathrm{gm}), 1.6(\mu \mathrm{g} / 1 \mathrm{~g})$ and $0.69(\mathrm{mg} / 100 \mathrm{gm})$ respectively. Hence concluded that complimentary food formulation with soaked and dried chia, basella leaves and other ingredients had very good nutritional profile and acceptability which can be introduced to children after 6 months age to meet the nutritional requirements.
\end{abstract}

\section{Introduction}

Infant feeding from birth to one year of life influences an individual's whole life. Breast milk alone can be used to feed infants properly for 4-6 months. This is a critical period because the rate of growth and development is more rapid than at any time in the life cycle. At birth, mother's milk alone is adequate for the infant. Requirements of all the nutrients progressively increase with the infant's growth. Simultaneously, the breast milk secretion in the mother comes down with time.

Thus, infants are deprived of adequate nutrients due to the dual factors of increased nutrient requirements and decreased availability of breast-milk. Usually, these changes occur at about 6 months of age. 
As infants grow and become more active following the first 6 months of life, however, breast milk alone falls short of providing the full nutritional requirements, where the gap keeps expanding with the increasing age of the infants and young children. Complementary feeding plays critical role in bridging these gaps. Also protects children from macro and micro nutrient deficiency disorders, growth faltering and irreversible changes during childhood. Hence, promotion of optimal growth in infants calls for introduction of adequate food supplements in the form of complementary foods in addition to continued breast feeding from the age of 6 months onwards. The nutritional adequacy of complementary foods is essential to the prevention of infant morbidity and mortality, including malnutrition and overweight. During infancy and early childhood (birth to 2 years), adequate amount of appropriate nutrition has paramount importance for full development of children's human potential (Motuma et al., 2016 and Krebs et al., 2011).

In several parts of the developing world, complementary feeding continues as a challenge to good nutrition in children of 6 23 months. In India, about $54.5 \%$ of children ages between 6 to 8 months had received any complementary foods in the previous day, but only $7 \%$ of breastfed children between the ages of 6 and 23 months met the minimum acceptable diet criteria. The challenges during complementary feeding are context specific, but many are common across settings. They are often characterized by poor feeding practices and poor dietary quality of homemade complementary foods (Anon, 1998 and Plessis, 2013).

Poor feeding practices are characterized by poor timing of complementary foods introduction (too early or too late); infrequent feeding; and poor feeding methods, hygiene, and child-care practices. Added to these is the poor dietary quality of the foods served, characterized as too little variety; inappropriate consistency (food is too thin or too thick); too few essential vitamins and minerals, especially vitamin A, iron, zinc, and calcium; too few essential fatty acids; and too few calories among non-breastfed infants. The poor quality and lack of diversity in foods adversely affects the children's growth and nutritional status (WHO, 2003 and Monte and Giugliani, 2004). Complementary feeding should be initiated at 6 months of child's age, adequate quantity and use of functional food ingredients (can boost the immunity, energy, protein with very good fatty acid profile). Millets like Finger millet rich in Calcium, Iron \& Zinc, Chia a super food with very good profile of fatty acids(Veda and Usha 2019).ground nut and soy for quality protein, green leafy vegetables for micronutrient and protective role are currently used in many preparations to provide nutritious food products to prevent malnutrition. Malnutrition in children hurts cognitive function and contributes to poverty by impeding a child's ability to lead productive lives, hence slows down national development. Thus, adequate and timely complementary feeding practices do not only regulate growth and functional development of a young child, but also appear to play a pivotal role in lifelong programming effects that regulate health, disease, mortality risks, neural function and behavior, and quality of life in adulthood. Keeping the above facts in background, present research work was carried out to develop complementary food formulation, sensory evaluation, nutrient and antinutrients analysis.

\section{Materials and Methods}

\section{Procurement of raw ingredients}

All ingredients (Finger millet, Soy, Groundnut, Chia seeds, Basella leaves (Basella Alb L.) Milk solids, Almond and 
Jaggery) required for the study are procured from Departmental stores in Bengaluru.

\section{Sample preparation}

Two hundred grams of finger millet was cleaned by hand picking and steeped in tap water in the ratio of 1:3 (w/v) and allowed to ferment at $28 \pm 2{ }^{\circ} \mathrm{C}$ for $48 \mathrm{~h}$. At the end of the germination, the grains were oven dried at 55 $\pm 5^{\circ} \mathrm{C}$, milled to fine flour and packaged as germinated finger millet flour.

One hundred grams of soybean was cleaned by hand picking, boiled in tap water in the ratio of $1: 5(\mathrm{w} / \mathrm{v})$ for one hour. The grains were dehulled manually and dried in a hot air oven at $50 \pm 5^{\circ} \mathrm{C}$.

The dried sample was then milled to fine flour (70 mm mesh screen). Groundnuts (100grams) were cleaned and roasted till it developed characteristic flavor and dehulled manually then dehusked followed by milling to get ground nut powder.

Fresh basella leaves (100grams) were steam blanched for 2 minutes, tray dried at $40 \pm 5^{\circ} \mathrm{C}$ for 4 hours followed by milling and sieving with $70 \mathrm{~mm}$ mesh.

Similarly, 200 grams of chia seeds were cleaned and100 grams were soaked in tap water in the ratio of $1: 3(\mathrm{w} / \mathrm{v})$ for 4 hour and dried in hot air oven at low temperature i.e., $30 \pm 5^{\circ} \mathrm{C}$ for 4 hours, after that dried chia seeds were milled to fine flour and used for Complementary food formulation I.

While remaining $100 \mathrm{~g}$ of chia seeds were tied in muslin cloth, kept in container with lid and exposed to steam for $10 \mathrm{~min}$.in pressure cooker and dried in oven to prepare Complementary food formulation II. The composition of complimentary food formulation was finger millet (50\%) chia seeds, soybean, jaggery, milk solids $10 \%$ each, ground nut 5\%, almonds $3 \%$ and Basella Alba leaves 2\%.

\section{Preparation of porridge and organoleptic} acceptability study

Porridge (Gruel) from the complementary food formulations was prepared with 1:3 flour to water ratio and subjected for organoleptic evaluation. Semi trained panel $(n=22)$ from the Department of Food Science and Nutrition, UAS, GKVK, Bangalore served as judges using Nine-point hedonic scale where 9 (like extremely) was the highest and 1 (dislike extremely) was the lowest score (Amerine, 1965). Best accepted formulation was further studied for macronutrients, micronutrients and antinutrients using different methods.

\section{Nutrient and antinutrient analysis of developed complementary food formulation}

Nutrient analysis of the developed complementary food formulations was conducted for moisture, protein by Kjeldhal plus method using Pelican Kelplus equipment (Nitrogen $x$ 6.25), fat was extracted refluxing thimbles in SOCS PLUS apparatus using petroleum ether (boiling point: $60-80^{\circ} \mathrm{C}$ ) as solvent, crude fiber, ash, using AOAC (2006) standard protocols. Energy and Carbohydrate content was computed by difference method.

Estimation of trace elements (minerals) by atomic absorption spectrophotometry (model AAS-2-6100)

The sample is treated with a mixture of mineral acid (tri or di acids) and heated for more rapid decomposition. The volatile constituents disappear and non-volatile mineral elements inter into the solution. Heating is continued until digest is reduced to 
a few $\mathrm{ml}$ of clear white residue. The residue is dissolved in $\mathrm{HCl}(6 \mathrm{~N})$, filtered and made to a known volume with distilled water for various elemental analyses and values are calculated as,

ppm of micronutrient $=\mathrm{ppm} \div 1000 \mathrm{X}$ volume of sample digest $\div$ weight of the sample X 1000 X dilution factor

\section{Antinutritional factors}

Antinutritional factors such as polyphenols, tannins and phytic acid were analysed using protocols listed below;

\section{Polyphenols}

Folin-ciocalteu reagent method (Singleton et al., 1999) where blue colour developed by polyphenols with FCR reagent in alkaline condition was measured at 650

\section{Tannin}

Using Folin-Denis reagents (AOAC, 1980)here tannins were estimated calorimetrically based on the measurement of blue colour formed by the reduction of phosphotungastomolybdic acid in alkali solution

\section{Phytic acid}

Wade reagent method (Gao et al., 2007), to find out the $\mu \mathrm{g}$ iron present in the test from the standard curve and calculate phytate $\mathrm{P}$ as per the equation

$\mu \mathrm{g}$ Fe $\times 15$ x 1
Phytate P (mg/100g sample) $=$
Weight of sample (g)

\section{Statistical analysis}

The results were analysed using a completely randomized design (CRD) to compare the variance. Suitable tests were applied to know the significant differences among the selected rice varieties at $\mathrm{P}<0.05$ following formulas given by Gomez and Gomez (1986).

\section{Results and Discussion}

Results of the present investigation are presented and discussed with the help of table and figures.

\section{Importance of ingredients used to develop complementary food}

Finger millet (Eleusine coracana L.) being an indigenous minor millet, used in the preparation of geriatric, infant food and health foods both in natural and malted forms. Chia seeds- a super food with excellent source of omega 3 fatty acid and quality protein well as micronutrient. It has excellent water holding capacity (Veda and Usha 2019). Soybean is rich source of protein and fats especially unsaturated fatty acids, helps emulsification and absorb the fat-soluble vitamins, A, D, E, \& K. Soybean product intake can prevent Non-Communicable Disease (NCD) including cancers and arterial sclerosis. Groundnut/Peanut contains many functional compounds like proteins, fibers, good source of niacin helpful in $\mathrm{CHO}$ metabolism, polyphenols, antioxidants, vitamins and minerals which can be added as a functional ingredient into many processed foods. Almonds provide a nutrient-dense source of vitamin $\mathrm{E}$, manganese, magnesium, copper, phosphorus, fiber, riboflavin, monounsaturated fatty acids and protein.

Basella is one of the versatile leafy green vegetable, fresh leaves are rich sources of several vital carotenoid pigment anti-oxidants such as B-carotene, lutein, zeaxanthin. It also contains good amounts of many B-complex vitamins such as folate, vitamin-B6 (pyridoxine), and riboflavin. 
$100 \mathrm{~g}$ fresh leaves provide $140 \mu \mathrm{g}$ or $35 \%$ of folates. This vitamin is one of the essential compounds for DNA production and growth. Basella leaves are good sources of potassium $(11 \%$ of RDA/100 g), manganese $(32 \%$ of RDA/100 g), calcium, magnesium, and copper.

Milk is one of the best sources of protein and a complete food after egg, hence concentrated milk in the form of solids support complete growth and development. Jaggery boosts secretion of digestive enzymes, thus improving digestion as well improving metabolism. Hence combination of these ingredients was used for formulation of compilatory food formulation to provide best nutrition in the beginning of the child's life which nourishes for long.

\section{Sensory evaluation}

Sensory evaluation explores specific characteristics of an ingredient or food product and helps to check whether a final food product meets its original specification. This provides objective and subjective feedback data to enable informed decisions to be made. The sensory tests for two variation of processed chia and basella enriched product were evaluated and described in Table 1. Sensory attributes like appearance, colour, texture, aroma, taste and overall acceptability were found highest in Formulation I (soaked and dried product) with the sensory score of 7.2, 7.0, 7.1, 6.8, and 7.2 respectively. The statistically analysed data showed a significant difference between two formulations for all the sensory attributes $(p>0.05)$ except for aroma. Basella incorporation did not affect the sensory parameters for the formulation. Since basella has very mild flavour, which will be lost during processing. Chia seeds are hydrophilic in nature. They hold up to 12 times their weight in water when soaked. Not only will presoaking chia seeds fill up the stomach faster and provides fullness. It will prevent from suffering of unwanted side effects. A dry chia seed followed by drinking of water expands in the esophagus and causes a blockage. Because they quickly swell after absorbing liquid, hence it is advised to consume chia seeds that have already been soaked in liquid or are served with a moist food (www.hsph.harvard.edu >Food Features and Veda and Usha 2019).

Similar findings are reported by Ruth et al., (2017) for micronutrient-rich complementary infant foods using rice (Oryza sativa, var. Togo Marshal) and six other Ghanaian food ingredients; soybean. cowpea, mango, red palm oil, groundnut and eggs. Among six blends, $70 \%$ rice, $25 \%$ soybean, $5 \%$ dried mango blend was most acceptable.

Based on the sensory evaluation scores, Complementary food formulation I was selected for further quality assessment.

\section{Nutritional composition of complementary food formulation}

Table 2 shows the proximate and mineral composition of best accepted complimentary food formulation I. Analysed values for moisture content was $14.4 \%$ and protein content, $28.30 \%$ and fat content was $18.8 \%$ which are quite high. This may be due to the addition of chia seeds, groundnut, soybean, almond and milk powder.

Hence, it can be considered as protein energy mix also. The inorganic content (ash) of product was $3.4 \%$ which represents the presence of total mineral content of the product. The major contribution might be from chia seeds, soybean, finger millet, basella leaves and milk powder. The crude fiber was $3.64 \%$, it is more than the recommended crude fiber intake for infants 
( $25 \mu \mathrm{g} /$ day). This might be due to chia seeds, millets and basella leaves. Developed formulation is also a good source of energy and carbohydrate.

Estimated calcium content of the formulation I was $302(\mathrm{mg} / 100 \mathrm{~g})$, zinc content $5.92(\mathrm{mg} / 100 \mathrm{~g})$ andiron content reported to be $2.7(\mathrm{mg} / 100 \mathrm{~g})$. The result revealed that the consumption of $100 \mathrm{~g}$ accepted formulation in the form of porridge per day will meet more than half of the daily requirement of the child.4-6 months of child age considered as aformative year, poor nutrition has immediate consequences of increased morbidity and mortality and delayed development of the brain and other nervous systems.

Similar nutrient-dense complementary food from amaranth and sorghum grains was developed by Okoth et al., (2017) for rehabilitating moderately acute malnourished children in a low-resource setting in Kenya. Steeping and germination was used to reduce the levels of antinutrients and enhance the bioavailability of minerals in the grains. Various steeped and germinated amaranth and sorghum grains formulations were developed.

The result shows that $90 \%$ amaranth-sorghum grains formulation had significantly $(\mathrm{F}=$ $32.133, \mathrm{P}<0.05)$ higher energy (5 kcal per $\mathrm{g}$ on dry weight basis) than the other formulations and a protein content of $14.4 \%$ and investigator concluded that developed product is higher than the estimated protein needs from complementary foods even for a 12-23 months child of low breast milk intake $(9.1 \mathrm{~g} / \mathrm{d})$.

Improper feeding practices and inadequate quality and quantity of complimentary foods impacts deficits in nutrients in early ages include impaired cognitive performance and reproductive outcomes and reduced work capacity and health status during adolescence and adulthood. Furthermore, malnutrition cycle persists with intergeneration impacts. When malnourished girl child grows up, she faces greater odds of having malnourished, low birth weight infant where, the failure to consume additional nutritious food in low resource settings has been identified as important risk factor resulting in excess disease and death of young child (Kreb et al., 2011; Motuma et al., 2016 and Muller \& Krawinkel, 2005). This necessitates the need for quality complementary food to meet the increased nutritional needs of the child.

\section{Antinutrients content of complimentary food formulation}

Antinutrients in foods are responsible for deleterious effects related to the absorption of nutrients especially micronutrients. Antinutrients and phytochemicals found in foods have been categorized as having both adverse and beneficial health effects in humans.

The chia and basella enriched formulation (I) was assessed for antinutritional contents such as polyphenol, tannin and phytic acid. The results are e represented in Table 3 and compared with respective standard curves in Fig, 1 to 3 . It shows that polyphenol, tannin and phytic acid 1 content were 0.84(mg/100gm), $1.6 \quad(\mu \mathrm{g} / 1 \mathrm{~g}) \quad$ and $0.69(\mathrm{mg} / 100 \mathrm{gm})$ respectively in the developed formulation.

These results are well supported from observations made by Omah et al., (2017)who formulated complementary food by using rice and soybean grains were milled to flours in the ratio of $90: 10,80: 20,70: 30,60: 40$ and 50:50 rice: soybean. Anti-nutrient composition of the complementary food blends showed oxalate, phytate, haemagglutinin and tannin to be within safe levels. 
Table.1 Organoleptic evaluation of Chia enriched commentary food formulations

\begin{tabular}{|l|c|c|c|c|c|c|}
\hline Formulations & Appearance & Colour & Texture & Aroma & Taste & $\begin{array}{l}\text { Overall } \\
\text { Acceptability }\end{array}$ \\
\hline $\begin{array}{l}\text { Complimentary } \\
\text { food formulation I }\end{array}$ & 7.2 & 7.0 & 7.1 & 6.8 & 7.2 & 7.2 \\
\hline $\begin{array}{l}\text { Complimentary } \\
\text { food formulation II }\end{array}$ & 6.3 & 6.3 & 6.0 & 6.6 & 6.3 & 6.4 \\
\hline F value & $* *$ & $* *$ & $* *$ & 1.271 & $* *$ & $* *$ \\
\hline Sem & 0.288 & 0.250 & 0.256 & 0.270 & 0.254 & 0.264 \\
\hline C.D Value @ 0.05 & 0.857 & 0.745 & 0.763 & 0.802 & 0.757 & 0.786 \\
\hline
\end{tabular}

** Significant at $(\mathrm{P}<0.01)$, NS-Non significant

Complimentary food formulation I contained soaked chia seeds

Complimentary food formulation II contained steamed chia seeds

Table.2 Proximate profile of best accepted complementary food formulation I with soaked chia seeds

\begin{tabular}{|l|l|l|}
\hline SI. No. & Nutrients & Quantity \\
\hline $\mathbf{1}$ & Moisture (\%) & 14.3 \\
\hline $\mathbf{2}$ & Protein (\%) & 28.3 \\
\hline $\mathbf{3}$ & Fat (\%) & 18.8 \\
\hline $\mathbf{4}$ & Ash (\%) & 3.4 \\
\hline $\mathbf{5}$ & Crude fibre (\%) & 3.64 \\
\hline $\mathbf{6}$ & Carbohydrate (\%) & 31.56 \\
\hline $\mathbf{7}$ & Energy (Kcal) & 407 \\
\hline $\mathbf{8}$ & Calcium (mg/100g) & 302 \\
\hline $\mathbf{9}$ & Zinc (mg/100g) & 5.92 \\
\hline $\mathbf{1 0}$ & Iron (mg/100g) & 2.77 \\
\hline
\end{tabular}

Table.3 Antinutrient content of best accepted complimentary food formulation I with soaked chia seeds

\begin{tabular}{|l|c|c|c|}
\hline Product & $\begin{array}{l}\text { Polyphenol } \\
(\mathbf{m g} / \mathbf{1 0 0 g m})\end{array}$ & $\begin{array}{l}\text { Tannin } \\
(\boldsymbol{\mu g} / \mathbf{1 g})\end{array}$ & $\begin{array}{l}\text { Phytic acid } \\
(\mathbf{m g} / \mathbf{1 0 0 g m})\end{array}$ \\
\hline $\begin{array}{l}\text { Complimentary } \\
\text { food formulation I }\end{array}$ & 0.84 & 1.6 & 0.69 \\
\hline
\end{tabular}


Int.J.Curr.Microbiol.App.Sci (2020) 9(5): 952-961

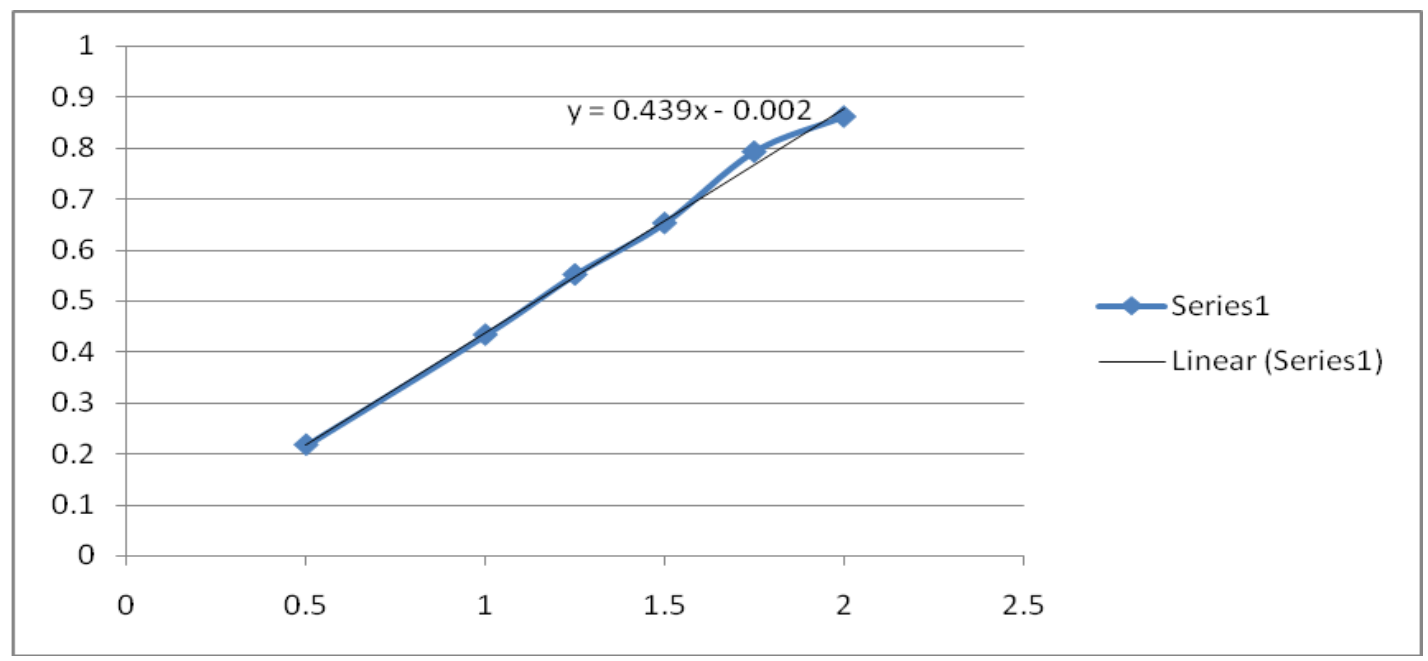

Fig.1 Phytic acid standard curve

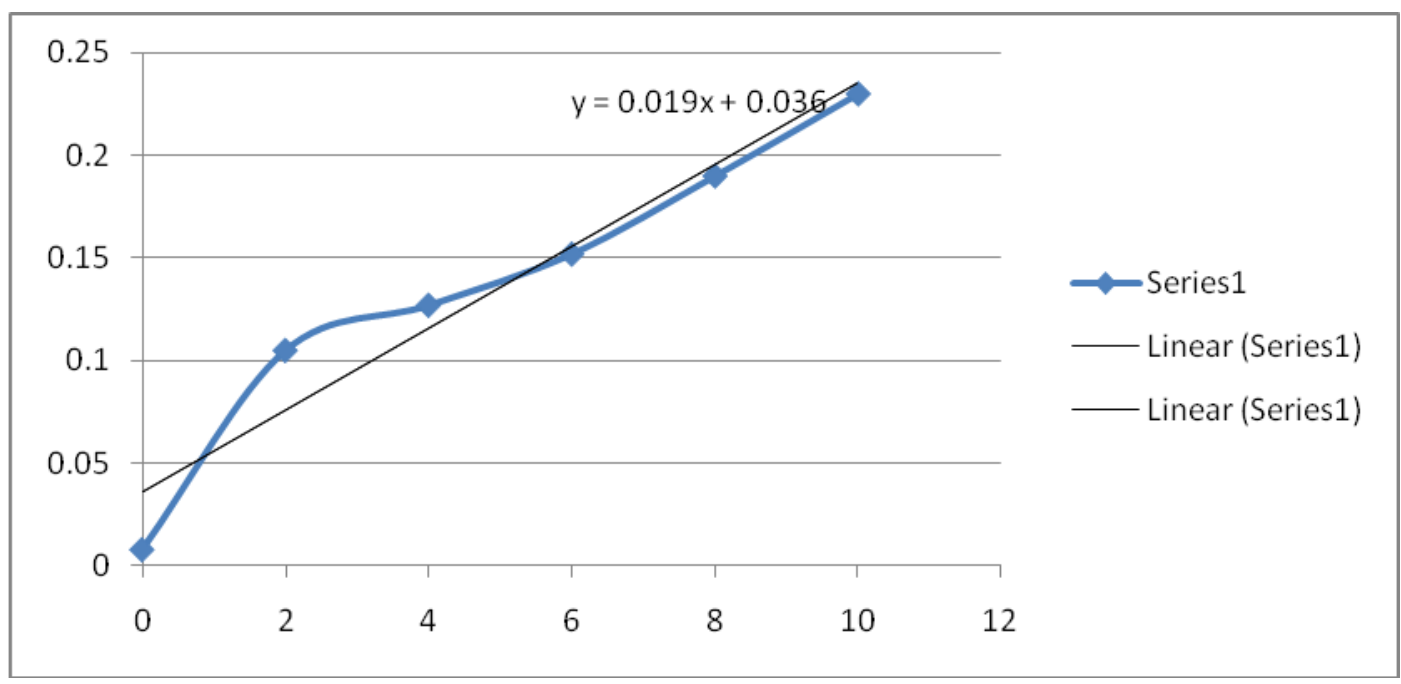

Fig.2 Tannins standard curve

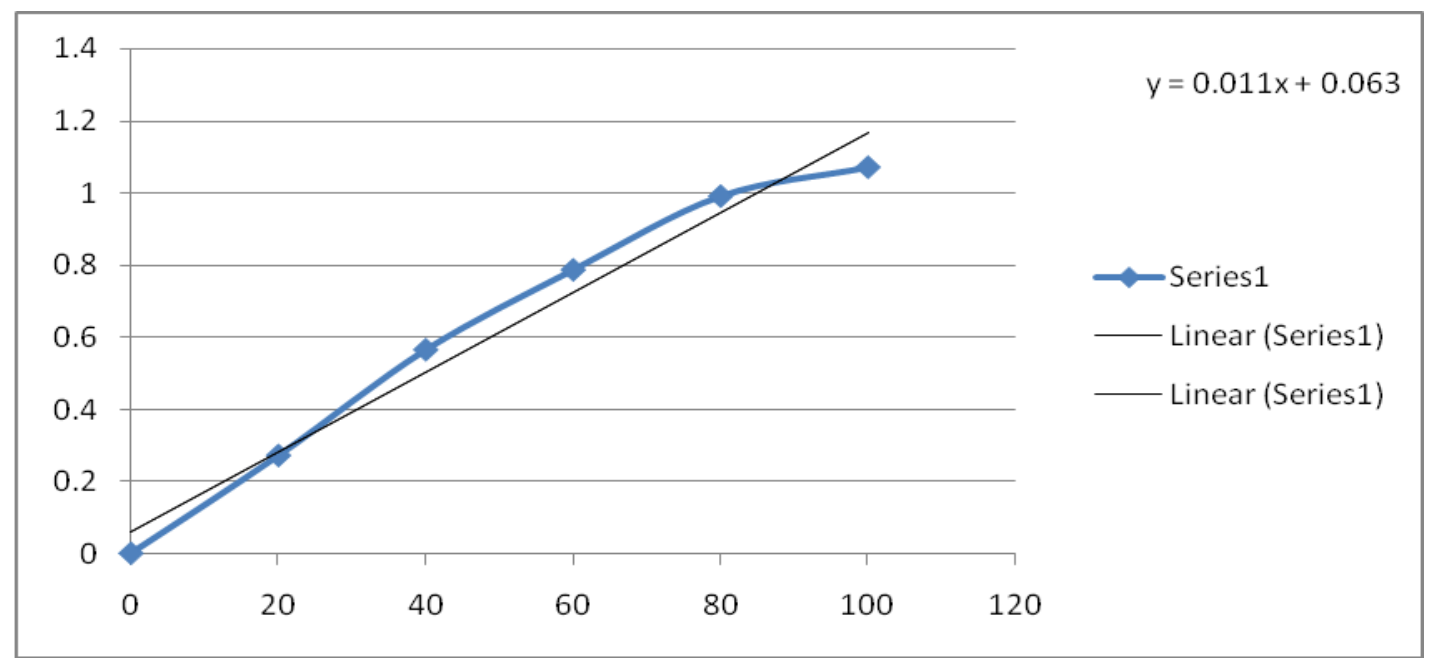

Fig.3 Polyphenols standard curve 
Blending of rice with soybean in various ratios for production of complementary food, affected the chemical, functional and sensory properties of the blends. Roasting of the grains before milling were instrumental in reducing the various anti-nutrients that are associated with rice and soybean to a minimum no- risk level.

Complementary feeding is nothing but, giving infants other foods or fluids along with breast milk. Complementary foods can be especially prepared for the infant or can be the same foods available for family members, modified in order to meet the eating skills and needs of the infant.

In this study an attempt was made to develop complimentary food formulations using finger millet, processed chia seeds and basella leaves to enhance the macro and micronutrient content.

Formulation with soaked and dried chia seed received best acceptance and reported good quantity protein, fat, energy, minerals and antinutritional factors with in the acceptable limits. Developing new products is a strategic area of the food industry to obtain health benefits that are expected from a nutritionally enriched food.

As a functional food ingredient, and in order to improve a nutritional quality, products such as chia seed basella enriched complimentary food formulation may be usable to make some of the manufactured foods.

\section{Acknowledgement}

We acknowledge DST project on Promotion of sustainable nutrition and empowerment of SC/ST women through nutri-farms in Chamarajanagar District. Govt. of India for financial assistance to carry out the research.

\section{References}

Amerine MA, Pangborn RM, Roesslereb, 1965, Principles of sensory evaluation of food. In: Food Science and Technology Monographs. pp.338-339. Academic Press, New York.

Anonymous, 1998, World Health Organization/United Nation Children's Fund. Complementary Feeding of Young Children in Developing Countries: A Review of Current Scientific knowledge. Geneva: WHO Press; http://www.who.int/nutrition/publicatio ns/infantfeeding/WHO_NUT_98.1/en/

AOAC (Association of Official Analytical Chemists), 2006, Official methods of analysis of the association of official analytical chemists (18th ed.)

AOAC, 1980, Official Methods of Analysis, Association of official agricultural chemists, Washington, D.C.

Gao Y, Shang C, Saghai Maroof MA., Biyashevrm, Grabauea, Kwanyuen P, Burton JW. and Buss GR,2007, Modified Colorimetric Method for Phytic Acid Analysis in Soybean Crop. Sci. 47: 1779-1803

Gomez KA and Gomez AA, 1986, Statistical Procedures in Agricultural Research (2nd Edition). John Willey and Sons, New York.

http://www.who.int/nutrition/publications/gs_ infant_feeding_text_eng.pdf

Krebs NF, Hambidge KM, Mazariegos M, Westcott J, Goco N, Wright LL, KosoThomas M, Tshefu A, Bose C, Pasha O, Goldenberg R, Chomba E, Carlo W, Kindem M, Das A, Hartwell T, Mcclure E,2011.Complementary feeding: a Global Network cluster randomized controlled trial, Complementary Feeding Study Group. BMC Pediatr. Jan 13; 11:4.

Monte CM, Giugliani ER, 2004, 
Recommendations for the complementary feeding of the breastfed child. J Pediatr (Rio J). Nov; 80(5 Suppl): S131-41.

Motuma Adimasu Abeshu, Azeb Lelisa,And Bekesho Geleta, 2016, Complementary Feeding: Review of Recommendations, Feeding Practices, and Adequacy of Homemade Complementary Food Preparations in Developing Countries, Front Nutr. 3: 41

Muller $\mathrm{O}$ and Krawinkel M,2005,Malnutrition and health in developing countries. CMAJ. Aug 2; 173(3):279-86.

Okoth J, Ochola S, Gikonyo N and Makokha A, 2017, Efficacy of amaranth sorghum grains porridge in rehabilitating moderately acute malnourished children in a low-resource setting in Kenya: A randomized controlled trial. Integrative Food, Nutrition and Metabolism. 4(4): 1-7

Omah EC, Umego EC, Onah PC, and Onu DA, 2017, Evaluation of complementary foods from blends of roasted rice and soybean flours. Innovare journal of food science 5:4

Plessis LM, Kruger HS, Sweet L. 2013, Complementary feeding: a critical window of opportunity from six months onwards. S Afr J Clin Nutr. 26 (3 Suppl): S129-40.

Ruth AP, Hannah O. Paa-NII T and Toah A, 2017, Complementary Foods from Rice and Six Other Ghanaian Food Ingredients Provide Sufficient Macro and Micronutrients for Infants 6-12 Month of age. Journal of Food and Nutrition Sciences; 5(3): 79-85

Singleton VL, Orthofer R, Lamuela-Raventos, RM, 1999, Analysis of total phenols and other oxidation substrates and antioxidants by means of FolinCiocalteu reagent. Methods Enzymol. 299, 152-178

Veda M. Hegde and Usha Ravindra, 2019, Effect of processing on nutritional composition of chia seeds poster presented at $7^{\text {th }}$ Bio Processing Conference held at CFTRI, Mysore on 14-16 ${ }^{\text {th }}$ December 2019, AFP 095.

World Health Organization/United Nation Children's Fund, 2003, Global Strategy for Infant and Young Child Feeding. Geneva: WHO Press

www.hsph.harvard.edu >Food Features: Chia Seeds | The Nutrition Source | Harvard T.H. Chan School.

\section{How to cite this article:}

Laxmibhai Belagali and Usha Ravindra. 2020. Quality Assessment of Chia and Basella alba (L.) based Complementary Food Formulation. Int.J.Curr.Microbiol.App.Sci. 9(05): 952-961. doi: https://doi.org/10.20546/ijcmas.2020.905.105 